\title{
Association between body composition parameters and non-specific low back pain in sedentary workers
}

\author{
Wondeuk Kima, Dongchun Park ${ }^{\mathrm{b}}$, Doochul Shin ${ }^{\mathrm{b}}$ \\ ${ }^{a}$ Department of physical therapy, graduate school of Kyungnam University, Republic of Korea \\ ${ }^{b}$ Department of physical therapy, College of health sciences, Kyungnam University, Republic of Korea
}

Objective: In clinical practice, there are a lot of exercise to reduce body weight or reduce the amount of body fat in order to solve back pain. However, many studies have contradicted the relationship between back pain and weight or body fat mass. The purpose of this study was to investigate the relationship between fat mass, body mass index and low back pain of office worker.

Design: Crossed-sectional study

Methods: Among the white-collar workers diagnosed with non-specific back pain by doctors, subjects who were not included in the exclusion criteria were selected to measure the subject's body fat mass, body mass index, pain intensity, and disability index due to back pain. The NPRS was used for the intensity of back pain of office workers, and the ODI was used for the degree of disability due to back pain. A body composition analyzer was used to measure the body fat mass and body mass index of white-collar workers.

Results: There was no significant difference between the two groups in the comparison between the normal group and the excessive group according to the criteria of fat mass and body mass index. In the correlation analysis of fat mass, body mass index, pain intensity, and disability index, it was found that there was a significant correlation between fat mass and body mass index. However, neither fat mass nor body mass index had a significant correlation with pain intensity and disability index.

Conclusions: The fat mass and body mass index of office worker do not affect low back pain.

Key Word: Low back pains, Body mass index, Obesity

서론

비-특이적 허리통증 이란 특별한 병리 해부학적 원인이 없이 허리와 엉덩이 주변에 통증이 나타나는 것을 말한다 [1]. 대부분의 사람들이 평생을 살아가면서 1 번 이상의 허 리통증을 경험 하며 허리통증 환자의 90 95\%가 비-특이 적인 허리통증으로 진단된다[2]. 이러한 비-특이적 허리통 증을 유발하는 위험요소에는 나이, 성별, 근력, 유연성, 체 격, 체중 등 다양한 요소들이 상관관계가 있는 것으로 보고 되고 있다[3-5]. 그 중에서도 체격과 체중은 중요한 위험요 소로 분류되고 있으며 많은 연구에서 과체중 또는 비만은 허리통증과 하지 방사통과 관련이 있다고 하였다 $[6,7]$.

체성분 분석은 개인의 건강상태를 나타내는 지표로 의
료현장에서 많이 사용되고 있다. 특히 우리나라에서 건강 검진 시 체성분 분석이 기본적으로 조사되고 다양한 목적 으로 사용되고 있다. 체성분 분석을 통해 얻어지는 체중, 체지방량, 체질량지수, 근육량 등은 고혈압, 당뇨, 동맥경 화, 근골격계 질환 등 다양한 질환들과 관련된다 $[8,9]$. Louise Murphy 등[10]은 퇴행성관절염의 평생 유병율이 체질량지수가 증가 할수록 커진다고 하였고, 체질량지수 가 정상인 사람이 비만인 사람에 비해 2/3정도의 평생 유 병율을 가진다고 하였다. 또한 Rahman Shiri 등[11]이 수 행한 체계적 고찰에 따르면 과체중과 비만이 허리통증의 유병율을 높인다고 하였다. Devender Singh 등[12]의 연 구에서 정상체중인 사람과 중증 비만인 사람의 물건 들어 올리기 작업 수행 시 허리벼 5 번과 엉치벼 1 번 사이의 추간

Received: Feb 26, 2021 Revised: Mar 12, 2021 Accepted: Mar 15, 2021

Corresponding author: Doochul Shin (ORCID https://orcid.org/0000-0002-8873-9541)

Department of Physical Therapy, Kyungnam University, 7 Kyungnamdaehak-ro, Masanhappo-gu, Changwon, Gyeongsangnam-do, 51767 Republic of Korea Tel: 82-55-249-2017 Fax: 82-505-999-2173 E-mail: icandox77@kyungnam.ac.kr

This is an Open-Access article distributed under the terms of the Creative Commons Attribution Non-Commercial License (http://creativecommons.org/licenses/ by-nc/4.0) which permits unrestricted non-commercial use, distribution, and reproduction in any medium, provided the original work is properly cited. Copyright (c) 2021 Korean Academy of Physical Therapy Rehabilitation Science 
판에 가해지는 압력을 측정한 결과 중증 비만인 사람이 정 상체중인 사람에 비해서 유의하게 높은 압력이 측정 되었 다. 이처럼 체성분 분석은 건강관리를 위해 중요한 지표로 인식되고 있고 과체중과 비만이 근골격계 통증에 영향을 준다는 연구결과들이 보고되고 있다[10-12].

하지만 Casey Okamoto 등[13]은 군인을 대상으로 한 연구에서 허리통증의 정도와 체지량지수와 연관성이 없다 고 하였고, Takeshi Endo 등[14]은 지역사회 거주노인을 대상으로 한 연구에서 체성분과 허리통증이 연관이 없다 고 하였다. 이처럼 허리통증과 체성분에 대한 연관성에 대 한 연구는 서로 상반된 연구 결과들이 존재하고 있다. 하지 만 여전히 임상현장에서는 허리통증과 체중 및 체질량지 수, 체지방률과 같은 체성분과의 연관성에 대한 인식이 높 으며 관련 운동프로그램을 적용하고 있다. 허리통증이 있 는 대상자들이 체성분의 변화를 위한 운동프로그램과 허 리부위의 근력 및 관절가동범위와 같은 신체의 기능을 개 선하기 위한 운동프로그램은 운동의 목적이 완전히 다르 기 때문에 신체성분과 허리통증과의 연관성에 대한 연구 는 여전히 중요하다고 할 수 있다. 비만의 선별기준으로 세 계보건기구는 체질량 지수를 제시하고 있다[13]. 하지만 체질량 지수는 간편하게 측정할 수 있다는 장점이 있으나 인종이나 체격, 근육량 등에 따라 실제로 신체에서 체지방 이 차지하는 비율과 차이가 날 수 있다[14]. 따라서 본 연 구에서는 대상자들의 비만도 측정을 위해 체질량 지수와 체지방량을 측정하여 허리통증과의 관계를 비교 하였다.

기존 체성분과 허리통증과의 연관성에 대한 연구들은 대상자들의 직업적인 특성들이 모두 다르기 때문에 서로 상반된 연구결과들이 나타났을 수 있다. 현대사회에서는 많은 사람들이 사무직 근로자로 일하고 있지만, 사무직 근 로자들을 대상으로 체성분과 허리통증과의 연관성에 대한 연구는 부족한 실정이다. 이에 본 연구에서는 사무직 근로 자의 체지방량과 체질량지수의 판정기준에 따른 허리통증 강도, 허리통증에 대한 장애지수의 차이를 비교하고 체지 방량, 체질량지수, 허리통증강도, 그리고 장애지수와의 상 관관계를 알아보고자 하였다.

\section{연구 방법}

\section{연구 대상}

본 연구는 의사로부터 비-특이적 허리통증으로 진단받 은 61 명의 사무직 근로자를 대상으로 실시 되었다. 대상자 모집은 서울소재 $\mathrm{S}$ 사 사내 물리치료실을 통하여 하였다. 2018년 5월부터 12월 까지 비-특이적 허리통증을 가진 사 무직 근로자가 연구에 참여 하였다. 대상자의 제외 기준은 단순 데이터 입력자, 오랜시간 서서 일하는자, 주당 컴퓨터 사용시간이 20 시간 이하인자, 허리통증 관련 약물을 복용
중인 자, 통증강도가 2점 이하인자, Oswestry disability index점수가 10점 이하인자로 하였다. 연구에 참여한 모 든 대상자는 연구의 절차와 목적에 대해 충분히 설명을 듣 고 동의서에 서명 하였다. 연구 진행에 대한 모든 과정은 $\mathrm{K}$ 대학교 연구윤리위원회의 승인을 거처 진행 되었다.

\section{연구 절차}

본 연구는 비-특이적 허리통증을 가진 사무직 근로자의 체지방량과 체질량지수의 판정기준에 따른 허리통증강도 와 장애지수를 비교하고 관련 변수들과의 상관관계를 알 아보기 위하여 시행되었다. 의사로부터 비-특이적 허리통 증을 진단 받은 사무직 근로자들 중에서 대상자의 제외기 준에 포함되지 않는 대상자를 선정하여 대상자의 체지방 량, 체질량지수, 통증강도, 허리통증으로 인한 장애지수를 측정하였다. 대상자들은 인터뷰와 설문작성을 통해 허리 통증 강도와 허리통증 장애지수를 측정한 후 체지방량과 체질량지수를 측정 하였으며 각 검사 간 휴식시간은 제공 되지 않았다. 사무직 근로자의 허리통증 강도를 위하여 숫 자통증척도(numeric pain rating scale; NPRS)를 사용하 였고, 허리통증으로 인한 장애의 정도를 위하여 오스웨스 트리 허리통증 장애지수(Oswestry disability index; ODI) 를 사용 하였다, 사무직 근로자의 체지방량과 체질량지수 을 측정하기 위하여 체성분 분석기(InBody370; Biospace, Republic of Korea)를 사용 하였다.

\section{Numeric Pain Rating Scale}

전반적인 통증의 강도를 측정하기 위해 숫자통증척도 를 사용 하였다. 환자는 자신의 통증 정도를 0 점에서 10 점 까지의 범위에서 선택하는 방식으로 측정되었고 0 점은 통 증이 없는상태, 10점은 극심한 통증을 의미한다.

\section{Korea Oswestry Disability Index}

허리통증으로 인한 신체적 장애 요인을 측정하기 위하여 한국어판 오스웨스트리 허리통증 장애지수(Dorea oswestry Disability Index; KODI)를 사용 하였다. KODI는 항목별 로 통증수준, 물건들기, 개인위생, 보행, 서있기, 앉아있기, 잠자기, 사회활동, 성생활 그리고 이동 및 여행의 10 개 항 목으로 구성되어 있다. 한국인의 정서상 민감한 정보인 성 생활과 관련된 항목을 제외한 9 개의 항목에 대하여 평가 하였다. 각 항목당 6 점 척도로 최소 0 점에서 최대 5 점으 로 총점은 45점이며 백분율로 환산된다. $020 \%$ 는 약간 장애, 21 40\%는 중등도 장애, $41 \sim 60 \%$ 는 심한 장애 그리 고 $60 \%$ 이상은 극심한 장애를 의미한다. ODI의 신뢰도는 Cronbach's $\alpha=0.85$ 이다

\section{Body composition}

신체적 특성을 측정하기 위하여 체성분 분석기(InBody370; 
Biospace, Republic of Korea)를 사용 하였으며 체지방량 과 체질량지수(Body Mass Index; BMI)를 측정 하였다. 체지방량은 신체에 있는 지방의 양으로 체중에서 체지방 이 차지하는 비율을 의미한다. 남성은 $25 \%$, 여성은 $30 \%$ 이상이면 비만으로 분류된다. 체질량 지수(Body Mass Index; BMI)는 체중 $(\mathrm{kg})$ 을 신장 $(\mathrm{cm})$ 의 제곱으로 나눈 값 으로 비만도를 판정하는 지표로 사용된다. 18.5 미만은 저 체중, 18.5 23은 정상, 23 25는 비만 전단계, 25 30은 1 단계 비만, 30 35는 2단계 비만 그리고 35이상은 33단계 비만으로 분류된다.

\section{자료 분석}

본 연구의 통계적 분석은 SPSS 21.0 을 사용 하였다. 체 지방량과 체질량지수의 판정기준에 따른 통증강도와 장애 지수의 비교는 독립표본 $\mathrm{t}$ 검정을 사용하였고, 체지방량, 체질량지수, 통증강도, 그리고 장애지수와의 상관관계를 알아보기 위하여 Pearson 상관계수를 사용하였다. 본 연구 의 통계분석을 위한 유의수준은 0.05 이하로 하였다.

\section{연구 결과}

61 명의 참여자 중 남자가 33 명(54.1\%), 여자가 28 명 (45.9\%)로 나타났다. 대상자들의 신장은 평균 $170 \mathrm{~cm}( \pm 7.31)$, 체중은 $88.2 \mathrm{~kg}( \pm 10.51)$, 체잘량 지수는 29.1 $( \pm 2.53)$ 인 것 으로 나타났다. 그리고 본 연구에 참여한 비-특이적 허리 통증의 가진 사무직 근로자의 허리통증강도는 평균 3.69 ( \pm 1.66$)$, 그리고 장애지수는 평균12.79( \pm 7.89$)$ 이었다(Table 1).

사무직 근로자의 체지방량을 기준으로 정상군과 과다 군 에서의 허리통증강도와 장애지수의 비교에서는 체지방 량의 판정기준에 따른 두 군간에 통계적으로 유의한 차이 가 없는 것으로 나타났다. 또한 체질량지수의 판정기준에 따른 정상군과 과다군의 비교에서도 허리통증강도와 장애 지수 모두 두 그룹간에 차이가 없는 것으로 나타났다 (Table 2).

Table 1. The General characteristics of subjects $(n=61)$

\begin{tabular}{|c|c|c|}
\hline Sex & $\mathbf{M} / \mathbf{F}$ & $33 / 28$ \\
\hline Height (cm) & & $170(5.63)$ \\
\hline Weight (kg) & & $63(6.68)$ \\
\hline BMI & & $63(6.68)$ \\
\hline NPRS & & $3.69(1.66)$ \\
\hline KODI & & $12.79(7.89)$ \\
\hline Computer use time & & $38.19(15.69)$ \\
\hline
\end{tabular}

Values are expressed as Mean (SD)

BMI: body mass index, NPRS: numeric pain rating scale, KODI: korean owestry disability index
본 연구의 체지방량, 체질량지수, 통증강도, 그리고 장 애지수와의 상관관계 대한 분석에서 체지방량과 체질량지 수는 서로 상관이 있는 것으로 나타났으나, 체지방량과 체 질량지수 모두 사무직 근로자의 허리통증강도와 장애지수 의 정도와는 상관이 없는 것으로 나타났다(Table 3).

Table 2. Comparison of pain intensity and disability index according to the criteria for determining obesty

\begin{tabular}{lll}
\hline & NPRS & KODI \\
\hline Normal body fat mass & $4.02(1.92)$ & $13.68(8.00)$ \\
Excessive body fat mass & $1.06(0.66)$ & $11.21(7.06)$ \\
$\mathrm{p}$ & 0.580 & 0.890 \\
Normal BMI & $3.77(1.85)$ & $12.65(8.22)$ \\
Excessive BMI & $3.50(1.34)$ & $12.36(7.01)$ \\
$\mathrm{p}$ & 0.510 & 0.880 \\
\hline
\end{tabular}

Values are expressed as Mean (SD).

NPRS: numeric pain rating scale, KODI: korean oswestry disability index, BMI: body mass index

Table 3. Correlation analysis with body mass index, body fat mass, pain intensity and disability index.

\begin{tabular}{lllll}
\hline & $\begin{array}{l}\text { Body fat } \\
\text { mass }\end{array}$ & BMI & KODI & NPRS \\
\hline Body fat mass & 1 & & & \\
BMI & $0.638^{* *}$ & 1 & & \\
KODI & 0.021 & -0.132 & 1 & \\
NPRS & 0.086 & -0.034 & $.654^{* *}$ & 1 \\
\hline
\end{tabular}

고찰

본 연구는 사무직 근로자의 체지방량과 체질량지수가 허리통증 및 장애지수에 미치는 영향을 알아보기 위해 실 시 하였다.

본 연구의 결과에서 사무직 근로자의 신체적 특성과 허 리통증 사이에는 유의한 상관관계가 없는 것으로 나타났 다. 체성분과 허리통증의 관계를 연구한 다양한 연구에서 비만이 허리통증에 중요한 위험요소 인것으로 조사된 경 우도 있었지만[10-12], 본 연구의 결과와 같이 비만이 허 리통증에 영향을 주지 않는 다는 결과를 보인 연구들도 있 었다[15-17]. 이러한 상충된 결과들은 연구대상자들의 직 업적 특성이나 생활양식과 같은 요소들을 고려하지 않고 조사되었기 때문이라고 생각된다.

Soungkyun등[18]의 연구에서 사무직 근로자를 대상으 로 신체적, 정신적 특성과 허리통증과의 상관관계를 분석 한 결과 체질량지수와 허리통증 사이에 유의한 상관관계 
가 없는 것으로 나타나 본 연구와 같은 결과가 나왔다. 사 무직 근로자는 주로 책상에 앉아서 컴퓨터와 관련된 업무 를 주로 행하고 이것은 장시간 앉은 자세를 유지해야 하는 특성을 가진다[19]. 사무직 근로자는 8시간 근무를 기준으 로 평균 6 7시간 동안 앉은 자세를 유지하고 허리통증은 앉은 자세를 유지하는 시간에 영향을 받는다[20]. Anna 등 [21]은 허리통증이 있는 609명을 대상으로 허리통증을 발 생시키는 위험요인에 대한 조사를 한 결과 장시간 앉은 자 세를 유지하는 생활 방식이 허리통증의 발생을 크게 증가 시켰고 활동량의 증가는 허리통증의 발생 빈도를 감소 시 킨다고 하였다. 따라서 비만과 관련된 지표들은 정적인 활 동을 주로 하는 사무직 근로자 보다는 육체노동을 많이 하 는 현장 근로자나 교대근무를 하는 간호사 등 동적인 활동 을 주로 하는 직업에서 더 많은 영향을 준다[22, 23]. 이러 한 이유로 사무직 근로자의 경우 체지방량이나 체질량지 수가 허리통증에 크게 영향을 주지 않은 것으로 생각된다.

사무직 근로자는 체지방량과 체질량지수와 같은 체성분 특성 보다는 장시간 앉은 자세 인하여 발생하는 근육 불균 형과 척추의 비정상 정렬이 허리통증에 더 큰 영향을 줄 것 으로 생각된다. Sunyue 등 [24]은 417명의 사무직 근로자를 대상으로 체질량지수와 업무환경이 허리통증과 관련이 있 는지를 조사한 결과 체질량지수는 허리통증과 관련이 없었 으며 업무환경중 컴퓨터 모니터의 위치가 허리통증과 관련 이 있다고 하였다. 본 연구의 이러한 결과는 사무직 근로자 의 허리통증을 개선하기 위하여 체지방량과 체질량지수를 개선하는 유산소 운동프로그램이나 식이요법 등을 적용하 는 것이 효율적이지 않을 수 있음을 알려주고 있다. 사무직 근로자의 비-특이적 허리통증을 개선하기 위해서는 근력, 관절가동범위 그리고 허리에 부담을 주는 움직임과 같은 신 체 기능적은 측면이나 자세와 정렬과 같은 요소들을 고려하 여 운동프로그램을 운영하는 것이 필요할 수 있겠다.

본 연구의 제한점은 체지방량과 체질량지수라는 비만 과 관련된 지표만을 사용하였기 때문에 근육량, 내장지방, 체수분, 단백질량 등 허리통증에 영향을 줄 수 있는 다양한 요소들을 고려하지 못했다. 또한 비-특이성 허리통증과 체 지방량과 체질량지수가 연관이 없다는 것은 제시하였지만 허리통증강도 및 장애지수에 영향을 미치는 다른 요소에 대해서는 제안하지 못한 것이다. 향후 이러한 점을 보완하 여 사무직 근로자의 비-특이적 허리통증에 영향을 미치는 다양한 요소들을 고려한 연구가 필요할 것으로 생각된다.

사무직 근로자의 체성분 특성 중 체지방량, 체질량지수 와 허리통증 강도, 허리통증 장애지수 사이에는 유의한 상 관관계가 없다. 따라서 사무직 근로자의 비-특이적 허리통 증을 개선하기 위하여 체지방량과 체질량지수를 개선하기 위한 운동프로그램이나 식이요법들은 효율적이지 않을 수 있다.

\section{참고문헌}

1. Maher C, Underwood M, Buchbinder R. Non-specific low back pain. Lancet. 2017;389:736-47.

2. Bardin LD, King P, Maher CG. Diagnostic triage for low back pain: a practical approach for primary care. Med J Aust. 2017;206(6):268-73.

3. Delitto A, George SZ, Van Dillen L, Whitman JM, Sowa G, Shekelle P, et al. Low back pain. J Orthop Sports Phys Ther. 2012;42:A1-57.

4. Furtado RN, Ribeiro LH, Abdo Bde A, Descio FJ, Martucci CE, Jr., Serruya DC. [Nonspecific low back pain in young adults: associated risk factors]. Rev Bras Reumatol. 2014;54:371-7.

5. Parreira P, Maher CG, Steffens D, Hancock MJ, Ferreira ML. Risk factors for low back pain and sciatica: an umbrella review. Spine J. 2018;18:1715-21.

6. Dario AB, Ferreira ML, Refshauge KM, Lima TS, Ordonana JR, Ferreira PH. The relationship between obesity, low back pain, and lumbar disc degeneration when genetics and the environment are considered: a systematic review of twin studies. Spine J. 2015;15:1106-17.

7. Zhang TT, Liu Z, Liu YL, Zhao JJ, Liu DW, Tian QB. Obesity as a Risk Factor for Low Back Pain: A Meta-Analysis. Clin Spine Surg. 2018;31:22-7.

8. Kuriyan R. Body composition techniques. Indian $\mathrm{J}$ Med Res. 2018;148:648-58.

9. Mazzoccoli G. Body composition: Where and when. Eur J Radiol. 2016;85:1456-60.

10. Murphy L, Schwartz TA, Helmick CG, Renner JB, Tudor G, Koch G, et al. Lifetime risk of symptomatic knee osteoarthritis. Arthritis Rheum. 2008;59: 1207-13.

11. Shiri R, Karppinen J, Leino-Arjas P, Solovieva S, Viikari-Juntura E. The association between obesity and low back pain: a meta-analysis. Am J Epidemiol. 2010;171(2):135-54.

12. Singh D, Park W, Hwang D, Levy MS. Severe obesity effect on low back biomechanical stress of manual load lifting. Work. 2015;51(2):337-48.

13. Brown AE. The Association of Life Insurance Medical Directors of America 100 years of progress. J Insur Med. 1989;21(3):156-63. 
14. Prentice AM, Jebb SA. Beyond body mass index. Obes Rev. 2001;2(3):141-7.

15. Okamoto CS, Dunn AS, Green BN, Formolo LR, Chicoine D. Correlation of Body Composition and Low Back Pain Severity in a Cross-Section of US Veterans. J Manipulative Physiol Ther. 2017;40(5): 358-64.

16. Endo T, Abe T, Akai K, Kijima T, Takeda M, Yamasaki M, et al. Height loss but not body composition is related to low back pain in community-dwelling elderlies: Shimane CoHRE study. BMC Musculoskelet Disord. 2019;20:207.

17. Brady SR, Mamuaya BB, Cicuttini F, Wluka AE, Wang Y, Hussain SM, et al. Body composition is associated with multisite lower body musculoskeletal pain in a community-based study. J Pain. 2015;16: 700-6.

18. Hong S, Shin D. Relationship between pain intensity, disability, exercise time and computer usage time and depression in office workers with non-specific chronic low back pain. Med Hypotheses. 2020;137:109562.

19. Yusuf M, Jagatia A, Mahmood Z, McCabe E, de Bruijn GJ, Smith L, et al. How do office workers respond to media coverage of sitting? Occup Med (Lond). 2019;69:372-5.

20. Urda JL, Larouere B, Verba SD, Lynn JS. Comparison of subjective and objective measures of office workers' sedentary time. Prev Med Rep. 2017;8:163-8.

21. Citko A, Gorski S, Marcinowicz L, Gorska A. Sedentary Lifestyle and Nonspecific Low Back Pain in Medical Personnel in North-East Poland. Biomed Res Int. 2018;2018:1965807.

22. Zhao I, Bogossian F, Turner C. The effects of shift work and interaction between shift work and overweight/obesity on low back pain in nurses: results from a longitudinal study. J Occup Environ Med. 2012;54:820-5.

23. Ibrahimi-Kacuri D, Murtezani A, Rrecaj S, Martinaj M, Haxhiu B. Low back pain and obesity. Med Arch. 2015;69:114-6.

24. Ye S, Jing Q, Wei C, Lu J. Risk factors of non-specific neck pain and low back pain in computer-using office workers in China: a cross-sectional study. BMJ Open. 2017;7:e014914. 